\title{
The Role of Neutrophil Extracellular Traps in Cancer
}

\author{
Bo-Zong Shao ${ }^{\dagger}, \mathrm{Yi} \mathrm{Yao}^{+}$, Jin-Ping $\mathrm{Li}^{+}$, Ning-Li Chai ${ }^{*}$ and En-Qiang Linghu * \\ Department of Gastroenterology, General Hospital of the Chinese People's Liberation Army, Beijing, China
}

Neutrophils are vital components of innate and adaptive immunity. It is widely acknowledged that in various pathological conditions, neutrophils are activated and release condensed DNA strands, triggering the formation of neutrophil extracellular traps (NETs). NETs have been shown to be effective in fighting against microbial infections and modulating the pathogenesis and progression of diseases, including malignant tumors. This review describes the current knowledge on the biological characteristics of NETs. Additionally, the mechanisms of NETs in cancer are discussed, including the involvement of signaling pathways and the crosstalk between other cancerrelated mechanisms, including inflammasomes and autophagy. Finally, based on previous and current studies, the roles of NET formation and the potential therapeutic targets and strategies related to NETs in several well-studied types of cancers, including breast, lung, colorectal, pancreatic, blood, neurological, and cutaneous cancers, are separately reviewed and discussed.

Keywords: neutrophil extracellular trap, cancer, neutrophil, immunity, inflammation

\section{INTRODUCTION}

Neutrophils are recognized as the most abundant leukocytes in the blood, comprising approximately $50 \%-70 \%$ of all circulating leukocytes in humans and $10 \%-25 \%$ in mice $(1-3)$. They are widely acknowledged as vital members of both innate and adaptive immune responses and defendants against exogenous invaders, including various kinds of bacteria, viruses, and fungi (4-6). Under microbial infection or foreign invasion, neutrophils are rapidly activated and accumulated, which contribute to the restriction and clearance by triggering reactive oxygen species (ROS) production, endocytosis, degranulation, etc. (7). In 2004, Brinkmann et al. observed a special form of neutrophil degranulation, consisting of DNA fibers decorated with granule proteins, which were initially termed neutrophil extracellular traps (NETs) (8). They revealed that the formation of extracellular DNA traps contributed to the constraining and killing of invasive bacteria (8). In the last 17 years since their initial discovery and definition, numerous studies have been devoted to uncovering the characteristics of NETs. Studies have also demonstrated the physiological and pathological functions of self-defensive mechanisms in various types of disorders via the involvement of inflammatory and immune responses (9-12). Recently, NETs have been demonstrated to be involved in the pathogenesis and progression of malignant tumors. An increasing number of studies have revealed the pro-tumor effects of NETs. These effects are mediated via mechanisms including the establishment of an inflammatory microenvironment and interaction with other pro-tumor mechanisms such as inflammasomes and autophagy (13-17). In 
this review, knowledge on the biological characteristics of NETs is presented. Furthermore, the roles of NETs and potential therapeutic targets and strategies related to NETs in several types of cancer, including breast, lung, colorectal, pancreatic, blood, neurological, and cutaneous cancers, is discussed in detail through a review of the latest related studies.

\section{PART I: BIOLOGICAL CHARACTERISTICS OF NETS}

NETs are extracellular strands of decondensed (unwound) DNA fibers in complex with histones and neutrophil granule proteins, including matrix metalloproteinase (MMP), neutrophil elastase (NE), myeloperoxidase (MPO), cathepsin G, complement factors, and other enzymatically active proteases and peptides (18-20). In the first few years since its initial report in 2004 (8), the term "neutrophil extracellular trap-osis (NETosis)" was widely used in related studies instead of NETs. The extensive use of the term NETosis was based on reports demonstrating that most extrusion of DNA strands resulted in their death, which allowed neutrophils to serve in immune reactions after their death (21-24). However, a strong concern was raised, since an increasing number of studies had reported that the occurrence of NETs does not necessarily lead to neutrophil death (9, 25-27). Therefore, it was strongly recommended by the Nomenclature Committee on Cell Death (NCCD) in 2018 that the term "NETosis" should be replaced with "NETs" or "NET formation" to include the DNA extrusion in the absence of cell death (28). Given this consideration, in this review, "NETs" or "NET formation" is used instead of "NETosis" in the following sections.

Under normal conditions, most DNA strands in neutrophils are highly wrapped around histones into heterochromatin within the nucleus $(18,29,30)$. The protein-DNA interactions largely constrain the potential energy of DNA to extend, which leads to transcriptional inactivity (31). Under certain stimuli, such as microbial and sterile agents in vivo or phorbol 12-myristate 13acetate (PMA), lipopolysaccharide (LPS), and intracellular calcium ion flux in vitro, the condensed DNA strands in neutrophils are uncoiled as fibrous polymers. The decondensation of DNA strands leads to the release of such potential energy, thus facilitating the formation of NETs (illustrated in Figure 1) $(32,33)$. To date, two proteases have been commonly acknowledged to be vital in the process of NET formation $(18,34-36)$. The first is peptidyl arginine deiminase 4 (PAD4), which catalyzes the conversion of arginine in histones to citrullines. Such citrullination significantly weakens the original positive charge of histones and weakens the strong histone-DNA binding, which leads to the decondensation of nuclear DNA and/ or mitochondrial DNA. Besides PAD4, the other vital protease is NE, which is considered to facilitate the destruction of histoneDNA binding by cleaving histones. Deficiency in either PAD4 or NE in mice has been shown to prevent generation of NETs (3739). After the decondensation of chromatins and disintegration of nuclei, DNA structures decorated with histones and granule proteins are extruded throughout the cellular membrane with the assistance of gasdermin D. Gasdermin D has been shown to function in the formation of pores, which results in the release of NETs $(40,41)$. However, several studies have demonstrated that PAD4 is not always necessary for NET formation. For instance, some researchers have argued that the role of PAD4 in NADPHoxidase (NOX)-dependent NETs remains controversial. They observed the formation of NETs in the absence of detectable histone deamination $(32,42,43)$. These studies indicate the complexity of the processes and mechanisms of NET formation.

To date, various signaling pathways have been shown to be involved in NET formation. Changes in the levels of signaling pathway-related proteins have been detected, including protein kinase $C(\mathrm{PKC})$, extracellular regulated protein kinase $1 / 2$ (ERK1/2), c-Jun N-terminal kinase (JNK), Akt, and Scr (4446). In addition, several mechanisms, including those involved in inflammasomes and autophagy, have been shown to interact with NETs in diseases (47-49). Since the initial discovery of bacterial infection as a stimulating factor for NETs, an increasing number of stimuli have been uncovered in the recent decade to trigger NET formation. In addition to bacteria, several other factors, including interleukin (IL)-8 (a major neutrophil chemoattractant) (50, 51), PMA (a PKC activator) (52-54), LPS (a component of gramnegative bacteria) $(55,56)$, certain kinds of toxins, intracellular calcium ion flux, ionomycin, and A23187 $(18,42)$ have been shown to stimulate NET formation. It is notable that the mechanisms for the stimulation of NET formation differ between in vitro and in vivo conditions. For instance, LPS has been demonstrated to be effective in inducing NET formation in vitro through direct stimulation of neutrophils. However, it has been shown that LPS can only induce NET generation by binding activated platelets (thrombocytes) in vivo (57). Due to the complexity of in vivo conditions and the relative limitations of research techniques, a limited number of studies have addressed the specific inducers of NET formation in vivo (33). To date, several factors, including exogenous infections such as bacteria and fungi $(10,58,59)$, inflammatory cytokine stimulation $(60,61)$ and interaction with activated platelets $(62)$ have been recognized as stimuli in vitro. However, few specific agents have been proven to be effective in inducing NET formation in vivo.

Based on the knowledge of the biological and morphological characteristics of NETs, several methods have been developed for the detection and monitoring of NET formation, including immunofluorescence, immunohistochemistry, intravital microscopy, live cell imaging, DNA-intercalating dying techniques, and immunoblotting. These methods mainly target NET-related proteins, such as PAD4, NE, MPO, and MMP (33, 63-65). By means of these techniques and methods for NET detection, NETs have been demonstrated to be highly involved in the pathogenesis and progression of several kinds of disorders, including inflammatory bowel disease (66-68), multiple sclerosis $(69,70)$, atherosclerosis $(71,72)$, ischemic stroke $(73)$, and some other autoimmune diseases $(11,20,74)$. Moreover, an increasing number of studies have uncovered the involvement of NETs in the onset and development of malignant tumors, which will be discussed in detail in the following sections. 


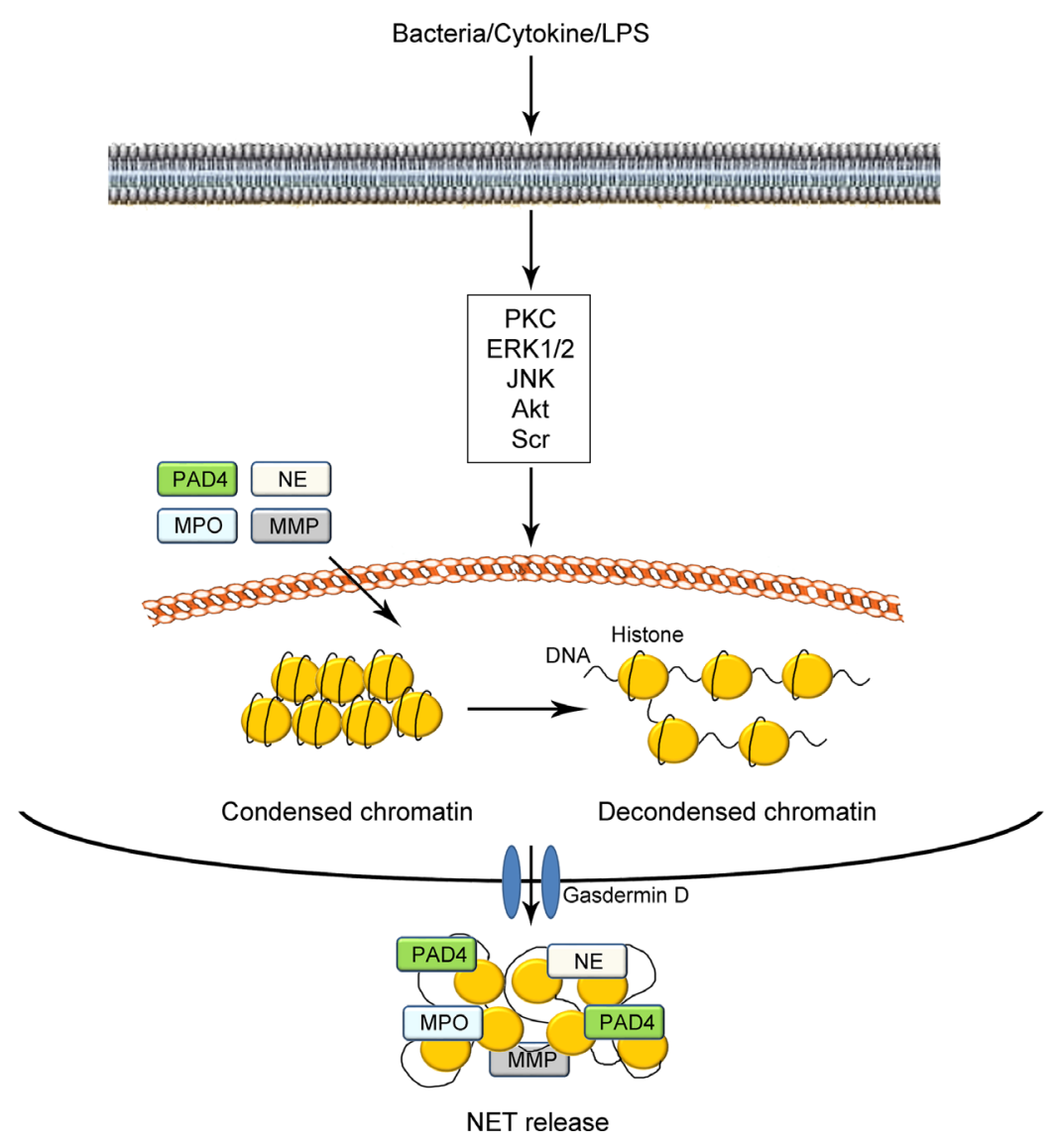

FIGURE 1 | Schematic illustration of NET formation. Under certain stimuli such as bacterial infection, cytokines, and LPS challenge, neutrophils are activated via the modulation of cellular signaling pathways mediated by PKC, EK1/2, JNK, Akt, Scr, and so on. The tight electrostatic binding between DNA strands and histones in nucleosomes is weakened, mediated by two kinds of proteases including PAD4 and NE. The decondensed DNA with citrullinated histones catalyzed by PAD4 are decorated with several granule proteins including PAD4, NE, MPO, MMP, and gasdermin D and expelled from neutrophils as NETs. NETs, neutrophil extracellular traps; LPS, lipopolysaccharide; PKC, protein kinase C; ERK1/2, extracellular regulated protein kinase 1/2; JNK, c-Jun N-terminal kinase; PAD4, peptidyl arginine deiminase 4; MMP, matrix metalloproteinase; NE, neutrophil elastase; MPO, myeloperoxidase.

\section{PART II: NETS IN CANCER}

\section{General Ideas on the Relations Between NETs and Cancer}

Notably, a search on the database of PubMed (www.ncbi.nlm. nih.gov/pubmed/) using the keywords "neutrophil extracellular traps" and ("cancer" or "tumor") yielded 672 results by June 2021, with studies published in the last 4 years (2018-2021) accounting for $65.9 \%$ (443 in 672). Demers et al. (75) first reported the role of NETs in cancer. Since then, the prevailing view is that NETs produce a pro-tumor effect through the promotion of cancer cell proliferation, differentiation, metastasis, and other pathological characteristics in various types of malignant tumors $(13,76-81)$. For instance, it was demonstrated that NE, an important granule protein in NET microvesicles, could degrade the extracellular matrix and induce the phosphatidylinositol-4,5-bisphosphate 3-kinase (PI3K) pathway in cancer cells. The induction of the PI3K signaling pathway promotes cancer cell proliferation and migration (76, 77). Another member of the granule proteins, MMP, was also reported to promote tumor growth and metastasis through proteolysis of the extracellular matrix $(13,78)$. In addition, it has been revealed that the proteases in NETs can induce the remodeling of laminin, which triggers the integrin signaling pathway in cancer cells and the awakening of dormant tumor growth (13). Moreover, Teijeira et al. demonstrated that CXCR1 and CXCR2 agonist-induced NETs could wrap and coat cancer cells, which shielded them from clearance and the cytotoxic effects of cytolytic cytotoxic T lymphocytes (CTLs) and natural killer (NK) cells (79). These data indicate that NETs may function as a physical barrier preventing the interaction between cancer cells and surrounding inflammatory and immune populations $(79,80)$. It was further revealed that the levels of intratumoral NETs and supranormal preoperative serum MPO-DNA, regarded as a NET marker, were significantly increased in metastatic cancer tissues (81). They 
showed that NETs could facilitate the growth of stressed cancer cells by altering their bioenergetics, while the inhibition of NETs leads to cancer cell death (81).

Cancer-associated platelet activation has been shown to facilitate tumor progression and metastasis through protecting cancer cells from shear forces and assault of immune cells, opening the capillary endothelium to induce the epithelialmesenchymal transition (EMT) program and secreting protumor growth factors, etc. (82-84). Patients with malignant tumors demonstrate an increase in platelet activation (82). NETs have been shown to contribute to the formation of arterial, venous, and cancer-associated thrombosis $(15,85)$. These findings suggest that targeting NETs may serve as a potential and promising approach to reduce thrombosis and limit tumor progression and metastasis.

In addition, NETs have also been regarded as an important member of the dynamic tumor immune microenvironment (TIME), which may contribute greatly to impeding metastatic dissemination $(51,86)$. Several factors have been revealed to contribute to the formation of the TIME. Among them, cancerassociated fibroblasts (CAFs) are regarded as one of the most vital pro-tumor factors. Regarding the influence of NETs on CAFs, it was reported that the formation of NETs originated from CAFs in pancreatic ductal adenocarcinoma, thus producing a pro-tumor microenvironment (87). For the mechanism by which NETs influence the conversion of normal fibroblasts into CAFs in tumors, a nuclear factor (NF)- $\mathrm{BB}$-dependent manner in stomal cells induced by activated neutrophils has been reported (88). Furthermore, the overwhelming production of fibroblast growth factors (FGFs) triggered by NETs in cancer was also shown to be a potential mechanism for the promotion of CAFs (89). However, due to the complexity of the conversion of normal fibroblasts to $\mathrm{CAF}$, more research is required to explore the specific mechanisms mediated by NET regulation.

Although abundant experimental data suggest the pro-tumor effect of NETs on cancer, it is not in the absence of controversy $(90,91)$. Some researchers have argued that baseline NETs could produce an anti-tumor effect by directly killing cancer cells or limiting tumor growth and metastasis via stimulation of the immune system (90). In addition, NETs have been shown to limit the growth of cancer-related intestinal microbiota populations, thus inhibiting the proliferation and metastasis of colorectal cancer cells (91). Therefore, to ultimately take advantage of NETs for cancer treatment, more knowledge should be gained regarding the precise regulation of NETs.

Currently, there is still little knowledge on the specific mechanisms of NET formation in cancer. Although some findings have been obtained, there is no consensus regarding this issue. A previous study revealed that NETs were produced by neutrophils in a toll-like receptor 4 (TLR4) and high-mobility group box 1 (HMGB1)-dependent manner in lung cancer cells (92). In addition, it has also been reported that the chronically inflammatory microenvironment contributes to the formation of NETs via an MPO-NETs-antineutrophil antibody (ANCA) axis in cancer $(93,94)$. Researchers have shown that NETs might act as a central factor in the neutrophil-NET-cancer cycle, thus aggravating the pathogenesis and progression of cancer. Other researchers have revealed that NETs might be associated with other cellular processes, including inflammasomes and autophagy, which will be discussed in the following sections.

\section{INFLAMMASOMES, NETS, AND CANCER}

Inflammasomes are multi-protein complexes that are widely regarded as important factors of inflammation and innate immunity responsible for the activation of inflammatory and immune responses through the recognition of pathogenassociated molecular patterns (PAMPs) or danger-associated molecular patterns (DAMPs) (95). To date, several types of inflammasomes have been reported, including the NOD-like receptor family, pyrin domain-containing 1 (NLRP1), NLRP2, NLRP3, NLR family caspase recruitment domain-containing protein 4 (NLRC4), and double-stranded DNA sensors absent in melanoma 2 (AIM2) (96-98). As previously reviewed by us, the activation of inflammasomes involves the cleavage of procaspase- 1 into caspase- 1 , which subsequently catalyzes the production and secretion of inflammatory cytokines, including IL-1 $\beta$ and IL-18 $(99,100)$. The involvement of NF- $\kappa B$ signaling in the initiation of inflammasome activation leads to increased production of inflammasome components $(99,100)$. Recently, numerous studies conducted by our laboratory and others have demonstrated the roles of inflammasomes in various diseases, including inflammatory bowel disease, multiple sclerosis, atherosclerosis, stroke, and malignant tumors (96, 101-103). In cancer, it has been revealed that the over-induction of inflammasomes largely influences cancer cell death, proliferation, and even tumor growth microenvironment, such as intestinal microbiota populations and fibroblasts, which indicates the wealth of putative inflammasome-based targeted therapies for cancer (104-110).

As important components in immune reactions, NETs have been shown to be closely linked to inflammasomes in some autoimmune diseases and cardiovascular disorders (19, 111, 112). For instance, it has been previously described that the formation of NETs by neutrophils could trigger the synthesis of inflammasome-related IL-1 $\beta$ and IL-18 in macrophages through cathelicidin LL-37-mediated potassium efflux from the cells. The production of IL-1 $\beta$ and IL-18 subsequently promotes NET formation during the occurrence of cardiovascular diseases (19, 113). Similar crosstalk between inflammasomes and NETs has been reported in cancer. It has been demonstrated that NETassociated serine proteases such as NE could act as alternative enzymes for processing inflammasome-related IL-1 $\beta$ and IL-18, which subsequently leads to the modulation of PGRN inactivation and MMP-9 activation in cancer (114). In addition, Albrengues et al. (13) reported in lung cancer that NETs and NETs-mediated extracellular matrix remodeling acted as critical mediators of awakening of dormant cancer cells by LPS-mediated formation of inflammasomes in mice. This process is mediated by the binding between NET-DNA and extracellular matrix protein laminin and bringing NE and MMP- 
9 to their substrates (13). To date, little evidence has been available regarding the crosstalk between inflammasomes and NETs in cancer $(13,114,115)$. However, future studies should further elucidate such interactions as they may unravel potential novel therapeutic strategies for the treatment of cancer.

\section{Autophagy, NETs, and Cancer}

Autophagy, commonly recognized as a vital metabolic mechanism relying on lysosomes, functions in degrading and recycling long-lived, misfolded proteins and damaged organelles to maintain cellular homeostasis (116-118). As previously described, under organic stress, such as nutrient deprivation or inflammatory loading, cytoplasmic materials are targeted and sequestrated into autophagosomes, which are regarded as the functional units of autophagy (119-121). The autophagosomes fuse with lysosomes to form autolysosomes (119-121). Notably, Yoshimori Ohsumi was awarded the 2016 Nobel Prize in Medicine or Physiology for exploring the cellular autophagy processes (122). Since its discovery by Christian de Duve in the 1960s (123), numerous studies from our laboratory and others have uncovered the involvement of autophagy in various diseases, including cardiovascular disorders, autoimmune diseases, metabolic abnormalities, malignant tumors, neurodegenerative diseases, and gastrointestinal diseases (124-129).

The influence of autophagy on the pathogenesis and progression of cancer tends to be regarded as a double-edged sword (130-134). In contrast, autophagy has been considered to maintain stemness, induce recurrence, and develop resistance of cancer cells to anticancer agents. The administration of rapamycin, an autophagy inducer, has been shown to be effective in alleviating cancer (131-133). Additionally, autophagy has also been reported to inhibit tumor initiation through the induction of autophagic cell death, and chloroquine, an autophagy inhibitor, has been used in anti-tumor therapy $(131,134)$. These studies indicate the complexity of autophagy mechanisms in cancer.

The dichotomous effects and complex mechanisms of interactions between autophagy and NETs have also been demonstrated in cancer. It has been reported that the induction of autophagy (formation of autolysosomes) in leukemia cells leads to the release of NETs, which results in the deterioration of acute promyelocytic leukemia (135). In addition, Boone et al. (136) revealed that NETs were upregulated in pancreatic cancer via receptor for advanced glycation end products (RAGE)-dependent/autophagy-mediated pathways. Regarding the effect of autophagy and NET crosstalk in cancer, it was previously revealed that the administration of chloroquine significantly reduced the hypercoagulability in pancreatic cancer by inhibiting NETs, suggesting a positive effect of suppressing autophagy-NET interaction in the alleviation of cancer (137). However, autophagy has been reported to be involved in the effects of interferon (IFN)- $\gamma$ on cell growth inhibition and cytotoxicity in lung epithelial malignancies via the induction of PAD4-mediated NETs (138). Consequently, to ultimately take advantage of interactions between autophagy and NETs in cancer treatment, further studies are required to explore this issue.

\section{PART III: NETS IN DIFFERENT TYPES OF CANCER}

During the 16 years since the initial discovery of NETs in 2004, an increasing number of researchers have focused on the study of NETs in cancer. Fortunately, to date, the effects of NETs in several popular types of cancer have been widely revealed to illustrate the whole picture. In this section, the roles of NETs and potential therapeutic targets and strategies related to NETs in several types of cancers, including breast, lung, colorectal, pancreatic, blood, neurological, and cutaneous cancers are described and discussed in detail based on the latest studies available in the current database (listed in Table $\mathbf{1}$ ).

\section{Breast Cancer}

Breast cancer is regarded as one of the three most commonly diagnosed cancers worldwide, especially in women (160). Breast cancer is one of the most studied type of cancer-related to NETs. It was first reported by Demers et al. (75) that, in a murine latestage breast cancer model, the formation of NETs corresponded with cancer-associated thrombosis in the lung. The formation of thrombosis contributed to a poor prognosis and cancer-caused death. In addition, the expression levels of PAD4 genes were shown to be high in murine breast cancer 4T1 cells and PAD4mediated NETs, which contributed to the release of cancer extracellular chromatin networks (CECN) both in vitro and in vivo (139). PAD4-mediated NETs were demonstrated to promote breast tumor growth and cancer metastasis into the lung, since the deletion of PAD4 genes in mouse models largely attenuated breast cancer cell proliferation and migration (139). In addition, Martins-Cardoso et al. (140) revealed that NETs promoted a pro-metastatic phenotype in human breast cancer cells by inducing the EMT program.

Regarding the exploration of therapeutic targets related to NETs in the treatment of breast cancer, a brilliant study by Yang et al. (141) uncovered a potential specific mechanism for the influence of NETs in breast cancer metastasis. In this study, the researchers revealed that the DNA components of NETs (NETDNA) could act as a chemotactic factor to attract breast cancer cells rather than merely "trap" them, thus leading to the occurrence of liver metastases in patients with early-stage breast cancer (141). They also suggested that the transmembrane protein CCDC25 might act as a potential NET-DNA receptor in breast cancer cells by sensing extracellular DNA. The activation of CCDC25 consequently enhanced cell motility through the subsequent activation of the ILK- $\beta$-parvin pathway. These data indicate an appealing therapeutic strategy that takes advantage of targeting CCDC25 for cancer metastasis prevention (141). It has been commonly revealed that patients with breast cancer are at a relatively higher risk of developing thrombosis. Gomes et al. (142) demonstrated that blockade of inflammasome-related IL-1 $\beta$ production and 
TABLE 1 | Potential pathophysiological and molecular mechanisms of NETs on different kinds of cancers.

\begin{tabular}{|c|c|c|}
\hline Cancer & Pathophysiological AND molecular mechanisms & Reference \\
\hline \multirow[t]{5}{*}{ BreAst cancer } & In correspondence with cancer-associated thrombosis occurrence in lung & $(75)$ \\
\hline & Release of cancer extracellular chromatin networks (CECN) & $(139)$ \\
\hline & Activating the epithelial-mesenchymal transition (EMT) program & $(140)$ \\
\hline & Acting as a chemotactic factor in assistant with a transmembrane protein CCDC25 & $(141)$ \\
\hline & Interaction with inflammasomes & $(142)$ \\
\hline \multirow[t]{4}{*}{ Lung cancer } & Activating integrin $\alpha 3 \beta 1$ signaling via NE/MMP 9-induced cleavage of laminin & (13) \\
\hline & Induced by a danger-associated molecular pattern protein high-mobility group box 1 (HMGB1) & $(92)$ \\
\hline & Induced by extracellular RNAs produced by lung cancer cells & $(143)$ \\
\hline & Preventing hypercoagulation and lung carcinogenesis & $(144)$ \\
\hline \multirow{4}{*}{$\begin{array}{l}\text { Colorectal } \\
\text { cancer }\end{array}$} & Inducing procoagulant activity (PCA) and leading to a close interaction with platelets and endothelial cells & $(145)$ \\
\hline & $\begin{array}{l}\text { NETs-associated carcinoembryonic Ag cell adhesion molecule } 1 \text { (CEACAM1) acted as an essential element for the interaction between } \\
\text { NETs and colorectal cancer cells }\end{array}$ & $(146)$ \\
\hline & Mediated by KRAS mutation transferred by exosomes & $(147)$ \\
\hline & Forming a positive loop connecting between NETs and colorectal cancer liver metastasis mediated by IL-8 & $(148)$ \\
\hline \multirow{4}{*}{$\begin{array}{l}\text { Pancreatic } \\
\text { cancer }\end{array}$} & Activating cancer-associated fibroblasts & $(87)$ \\
\hline & Modulating cell-cell junctions & $(149)$ \\
\hline & $\begin{array}{l}\text { Epithelial-mesenchymal transition via IL-1ß/epidermal growth factor receptor (EGFR)/extracellular regulated protein kinase (ERK) } \\
\text { pathway }\end{array}$ & $(150)$ \\
\hline & Stimulating platelets and release of tissue factor via autophagy & $(137)$ \\
\hline \multirow[t]{4}{*}{ Blood cancerS } & Stimulating citrullination of histone H3 via the activation of PAD4 in multiple myeloma & $(151)$ \\
\hline & Activating platelets in myeloproliferative neoplasms & $(152)$ \\
\hline & Mediated by the Janus kinase (JAK)-activator of transcription (STAT) signaling & (153) \\
\hline & Inhibited by ibrutinib in chronic lymphocytic leukemia & $(154)$ \\
\hline \multirow{2}{*}{$\begin{array}{l}\text { Neurological } \\
\text { cancers }\end{array}$} & Involved by highly sensitive Troponin T (hsTnT) & $(155)$ \\
\hline & Regulated by the high-mobility group box 1 (HMGB1)/advanced glycation end products (RAGE)/IL-8 axis & $(156)$ \\
\hline \multirow{3}{*}{$\begin{array}{l}\text { Cutaneous } \\
\text { cancers }\end{array}$} & Promoting the spontaneous and immunotherapy-induced adverse reaction of melanoma & (157) \\
\hline & Association of IL-8 and NETs & $(158)$ \\
\hline & Producing an anti-tumor polarization of tumor-associated neutrophils mediated by type I interferons (IFNs)-related NETs suppression & (159) \\
\hline
\end{tabular}

secretion attenuated cancer-associated thrombosis in a NETsdependent breast cancer model, indicating the vital role of the crosstalk between NETs and inflammasomes in the treatment of breast cancer.

\section{Lung Cancer}

Lung cancer is the most diagnosed and frequent cause of cancerrelated deaths worldwide, with approximately 1.8 million newly diagnosed patients and 1.6 million deaths each year (161). Thus far, NETs have been demonstrated to modulate the biological characteristics of lung cancer cells, thus influencing the pathogenesis and progression of lung carcinoma. For instance, a brilliant study published in Science revealed that sustained lung inflammation mediated by smoke exposure or nasal instillation of LPS could awaken dormant cancer cells and facilitate metastasis through the induction of NET formation (13). Mechanistic analysis revealed that this process was potentially via NE/MMP-9-induced cleavage of laminin, which subsequently led to the activation of integrin $\alpha 3 \beta 1$ signaling in dormant cancer cells (13). However, it is worth mentioning the difference between lung cancer patients and tumor-bearing mice models pointed out by Arpinati et al. (162). They argued in a recent study that no predisposition of neutrophils to release NETs in patients with lung cancer was found to be similar to that in mice compared with healthy controls. These results indicate that attention should be paid to the translation of experimental results obtained from animal studies into clinical applications (162).

Regarding therapeutic targets related to NETs in lung cancer, it was previously revealed that the DAMP protein HMGB1 released by lung cancer cells contributes to the induction of NETs that was dependent on the activation of TLR4 (92). In addition, extracellular RNAs (exRNAs) produced by lung cancer cells have also been demonstrated to induce NET formation, which promotes cancer cell proliferation and migration (143). In addition to exploring therapeutic targets, some researchers have focused on the development of therapeutic strategies for the treatment of lung cancer-related to NETs, using certain natural compounds. Recently, Li et al. (144) revealed that emodin, the main bioactive component of Rheum palmatum, could significantly prevent hypercoagulation and lung carcinogenesis by suppressing NET formation in lung cancer animal models. However, most related research is still in the stage of animal models. Therefore, more clinical studies are required for the development of cancer therapies based on NETs.

\section{Colorectal Cancer}

According to the analyzed data in 2019, colorectal cancer is considered to be the fourth most deadly cancer worldwide, with 900,000 deaths annually (163). Aging, western lifestyle, and bowel inflammatory conditions (e.g., inflammatory bowel diseases) serve as risk factors for the oncogenesis of colorectal 
cancer $(163,164)$. Richardson et al. (165) demonstrated that patients with colorectal cancer have significantly increased NET formation compared with healthy volunteers, and high levels of NETs were shown to be associated with adverse patient outcomes. Furthermore, NETs have been reported to be involved in venous thrombogenesis in patients with colorectal cancer via the induction of procoagulant activity (PCA), which led to a close interaction with platelets and endothelial cells (145). These data indicate that targeting NETs may be a potential and promising way to tackle thrombosis in colorectal cancer.

Exploring potential therapeutic targets related to NETs in colorectal cancer, Rayes et al. (146) revealed that NETsassociated carcinoembryonic antigen cell adhesion molecule 1 (CEACAM1) acts as an essential element for the interaction between NETs and colorectal cancer cells, and deficiency in CEACAM1 significant decreases cancer cell adhesion, migration, and metastasis. Regarding the induction of NET formation, KRAS mutation has been shown to contribute to neutrophil recruitment and NET formation through exosomes in colorectal cancer, which uncovered a novel mechanism of regulation of NET formation in colorectal cancer (147). In addition, IL-8, a tumor inflammatory cytokine, has been reported to be part of a positive loop connecting NETs and colorectal cancer liver metastasis (148). However, further studies are required to develop effective therapeutic strategies for colorectal cancer, taking advantage of these targets.

\section{Pancreatic Cancer}

Pancreatic cancer is a highly lethal cancer in the absence of a standard screening program since most patients remain asymptomatic until they reach an advanced stage (166). A clinical study demonstrated that tumor-infiltrating neutrophils (TINs) and their generated NETs could be treated as prognostic factors for pancreatic cancer independent of the TNM staging system (167). NETs have also been shown to promote liver micrometastasis in pancreatic cancer by activating CAFs (87). Notably, it has been commonly recognized that pancreatic cancer induces a hypercoagulable state, which could result in clinically apparent thrombosis (168). An increasing number of studies have demonstrated the influence of NETs on hypercoagulability and thrombogenesis (137, 149, 168). For instance, $\mathrm{Yu}$ et al. (149) showed an association between the upregulation of NETs and PCA in patients with pancreatic cancer through the modulation of cell-cell junctions. Furthermore, Hisada et al. (169) revealed that neutrophils and NETs contribute to venous thrombosis in mice bearing human pancreatic tumors and patients with pancreatic cancer, indicating a thrombogenic effect of NETs in pancreatic cancer.

Regarding therapeutic targets related to NETs in pancreatic cancer, Jin et al. (150) revealed that NETs could promote migration and invasion of pancreatic cancer cells via EMT and the IL-1 $\beta$ /epidermal growth factor receptor (EGFR)/ERK pathway. These results indicate that blockade of the IL-1 $\beta$ / EGFR/ERK signaling pathway might serve as a potential strategy for the alleviation of pancreatic cancer. In addition, it has been reported that targeting the interaction between NETs and autophagy reduces hypercoagulability in pancreatic cancer
(137). They showed that the administration of chloroquine for the blockade of autophagy significantly lowered the rates of venous thromboembolism in patients with pancreatic cancer by suppressing autophagy-related NET formation. However, further studies are needed for successful clinical application.

\section{Blood Cancers}

Blood cancers are a group of "invisible" cancers, as tumors are seldomly observed in blood cancers (170). In a broad sense, blood cancers include leukemia, multiple myeloma, and malignant lymphoma. Regarding the effects of NETs on blood cancers, a statistically significant increase in NET levels was found in patients with multiple myeloma (MM) compared to healthy volunteers both in the serum and plasma (171). Furthermore, MM cells have been shown to stimulate citrullination of histone $\mathrm{H} 3$ and subsequently lead to the formation of NETs through the activation of PAD4 (151). In addition, NETs have been reported to contribute to thrombogenesis, a major cause of mortality in patients with myeloproliferative neoplasms (MPNs) via platelet activation (152).

Regarding the therapeutic targets related to NETs in blood cancers, it was reported by Wolach et al. (153) that NET formation was increased in mice MPN models via the Janus kinase (JAK)-activator of transcription (STAT) signaling. The administration of ruxolitinib, a JAK2 inhibitor, effectively suppressed NET formation and reduced thrombosis. In addition, NET formation has been previously shown to contribute to the pathogenesis of chronic lymphocytic leukemia (CLL), and ibrutinib, a widely used chemotherapeutic drug, alleviated CLL by slightly impairing NET production in patients with CLL (154). Based on these findings, the modulation of NET formation may be a potential and promising therapeutic strategy for the treatment of blood cancers.

\section{Neurological Cancers}

Neurological cancers are defined as a group of primary or metastatic cancers of the central nervous system (CNS) (172). According to the World Health Organization (WTO) in 2016 (173), neurological cancers comprise diffuse astrocytic and oligodendroglial tumors, other astrocytic tumors, ependymal tumors, other gliomas, lymphomas of the CNS, and metastatic cancers. Regarding the role of NETs in neurological cancers, it was previously reported that NETs could significantly promote cancer-associated arterial microthrombosis in cancer patients presenting with ischemic stroke and large elevations of highly sensitive troponin $\mathrm{T}$ (hs-TnT) (155). In addition, in patients with high-grade gliomas, a high level of thrombogenic NETs produced by neutrophils was detected, which resulted in an increase in venous thromboembolism (VTE) (174).

Regarding therapeutic targets related to NETs in neurological cancers, Zha et al. (156) revealed that NETs generated by TINs mediated the crosstalk between glioma and tumor microenvironment in patients with malignant glioma. These effects were demonstrated to be regulated by the HMGB1/RAGE/ IL-8 axis. However, little is known about the specific mechanisms of NET formation in neurological cancers. Consequently, further studies are required to ultimately develop therapies targeting NETs. 


\section{Cutaneous Cancers}

Cutaneous cancers, also known as "skin cancers", are a group of cancers that occur in the skin tissue. Cutaneous cancers are divided into melanoma and non-melanoma, with the latter including basal cell carcinoma and squamous cell carcinoma (175). The mechanisms underlying the pathogenesis and progression of cutaneous cancers are complex and remain unclear. To date, modern research has demonstrated that NETs are closely related to cutaneous cancers. NETs have been reported to promote inflammation-mediated skin tumor cell growth in mouse models (176). NETs have also been shown to contribute to spontaneous and immunotherapy-induced adverse reactions of melanoma murine models (157). In addition, similar to other tissues, NET-mediated thrombosis was also found in the skin tissue, indicating the positive effects of NETs on thrombosis in cutaneous disorders (177).

IL- 8 has been reported to be a potential therapeutic target related to NETs, since the association of IL- 8 and NETs was revealed in patients with metastatic melanoma (158). In addition, type I IFNs, widely used anti-inflammatory agents, have been shown to induce anti-tumor polarization of tumor-associated neutrophils in murine models and melanoma patients. The transfer of neutrophils into an anti-tumor disturbs the formation of NETs and thus produces a tumor-suppressive effect (159). However, additional studies are needed to develop therapies for cutaneous cancers that target NETs.

\section{CONCLUSION}

Overall, recent studies have demonstrated the important roles of NETs in cancer through modulation of the biological characteristics of cancer cells including proliferation, differentiation, and metastasis and induction of cancer-related thrombogenesis (illustrated in Figure 2). So far, we have gained significant knowledge on the biological features and regulation of NET formation, as well as the mechanisms of the effects of NETs on different types of cancers. However, because of the limitations of current studies, the specific mechanisms of NETs and the crosstalk between NETs and other cancer-related processes, including inflammasomes and autophagy, remain unclear. The specific mechanisms underlying NET formation also remain unclear. Therefore, additional studies are required for the successful application of knowledge regarding NET formation and function in clinical practice through the development of novel and promising therapeutic strategies against cancer.

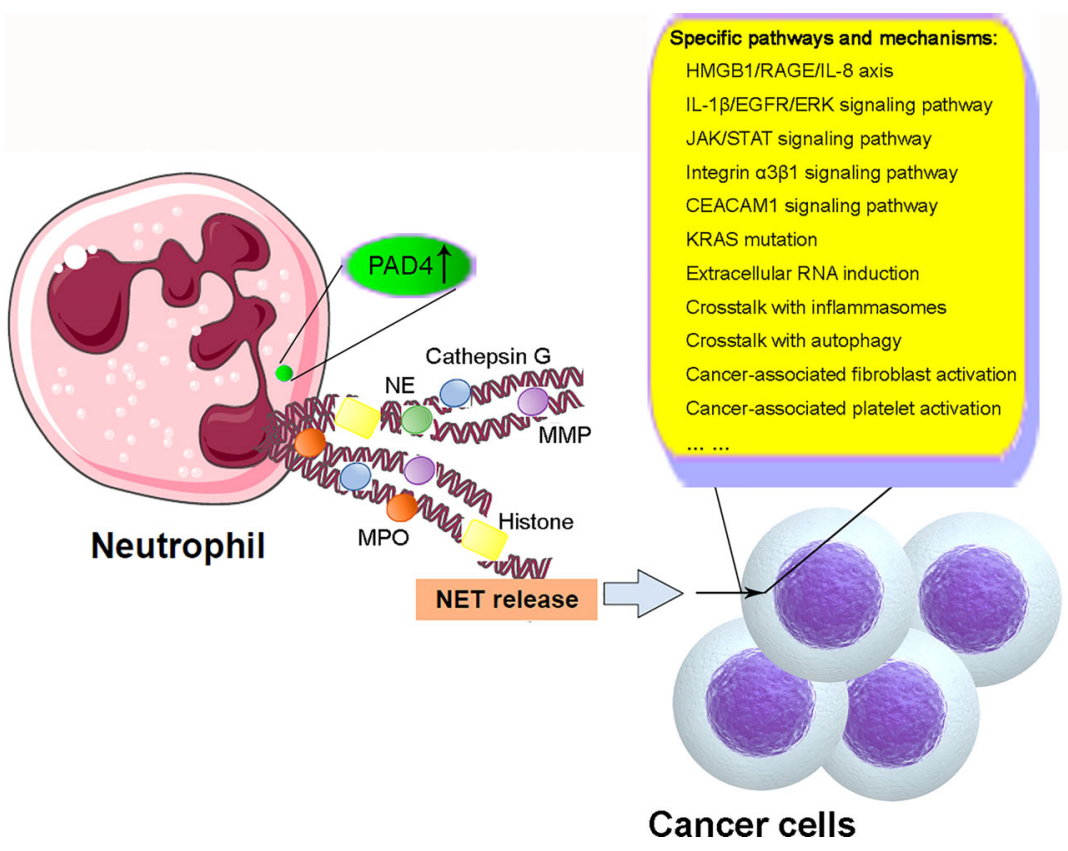

FIGURE 2 | Schematic illustration of mechanism of NETs in cancer. Under cancer-related stimulation, the level and function of PAD4 are enhanced, leading to the citrullination of histones and subsequent decondensation of chromatins. NET microvesicles with DNA-structural fibers decorated by histones, MMP, NE, MPO, cathepsin G, and other granule proteins are extruded from neutrophils. NET formation modulates the biological characteristics of cancer cells in proliferation, differentiation, migration, and metastasis through the involvement and crosstalk with some specific pathways and mechanisms including HMGB1/RAGE/IL-8 axis, IL13/EGFR/ERK signaling pathway, JAK/STAT signaling pathway, integrin $\alpha 3 \beta 1$ signaling pathway, CEACAM1 signaling pathway, KRAS mutation, extracellular RNA induction and crosstalk with inflammasomes and autophagy, and cancer-associated fibroblast and platelet activation. NETs, neutrophil extracellular traps; PAD4, peptidyl arginine deiminase 4; MMP, matrix metalloproteinase; NE, neutrophil elastase; MPO, myeloperoxidase; HMGB1, high-mobility group box 1; RAGE, advanced glycation end products; EGFR, epidermal growth factor receptor; ERK, extracellular regulated protein kinase; JAK, Janus kinase; STAT, activator of transcription; CEACAM1, carcinoembryonic Ag cell adhesion molecule 1. 


\section{AUTHOR CONTRIBUTIONS}

B-ZS and YY retrieved concerned literatures and wrote the manuscript. J-PL designed the table and figures. E-QL and $\mathrm{N}$-LC revised the manuscript. All authors contributed to the article and approved the submitted version.

\section{REFERENCES}

1. Rosales C. Neutrophils at the Crossroads of Innate and Adaptive Immunity. J Leukoc Biol (2020) 108:377-96. doi: 10.1002/JLB.4MIR0220-574RR

2. He R, Chen Y, Cai Q. The Role of the LTB4-BLT1 Axis in Health and Disease. Pharmacol Res (2020) 158:104857. doi: 10.1016/j.phrs.2020.104857

3. Mestas J, Hughes CC. Of Mice and Not Men: Differences Between Mouse and Human Immunology. J Immunol (2004) 172:2731-8. doi: 10.4049/ jimmunol.172.5.2731

4. Brinkmann V, Zychlinsky A. Neutrophil Extracellular Traps: Is Immunity the Second Function of Chromatin? J Cell Biol (2012) 198:773-83. doi: $10.1083 /$ jcb. 201203170

5. Bianchi M, Hakkim A, Brinkmann V, Siler U, Seger RA, Zychlinsky A, et al. Restoration of NET Formation by Gene Therapy in CGD Controls Aspergillosis. Blood (2009) 114:2619-22. doi: 10.1182/blood-2009-05-221606

6. Branzk N, Lubojemska A, Hardison SE, Wang Q, Gutierrez MG, Brown GD, et al. Neutrophils Sense Microbe Size and Selectively Release Neutrophil Extracellular Traps in Response to Large Pathogens. Nat Immunol (2014) 15:1017-25. doi: 10.1038/ni.2987

7. Mayadas TN, Cullere X, Lowell CA. The Multifaceted Functions of Neutrophils. Annu Rev Pathol (2014) 9:181-218. doi: 10.1146/annurevpathol-020712-164023

8. Brinkmann V, Reichard U, Goosmann C, Fauler B, Uhlemann Y, Weiss DS, et al. Neutrophil Extracellular Traps Kill Bacteria. Science (2004) 303:15325. doi: 10.1126/science.1092385

9. Papayannopoulos V. Neutrophil Extracellular Traps in Immunity and Disease. Nat Rev Immunol (2018) 18:134-47. doi: 10.1038/nri.2017.105

10. Sollberger G, Tilley DO, Zychlinsky A. Neutrophil Extracellular Traps: The Biology of Chromatin Externalization. Dev Cell (2018) 44:542-53. doi: 10.1016/j.devcel.2018.01.019

11. Lee KH, Kronbichler A, Park DD, Park Y, Moon H, Kim H, et al. Neutrophil Extracellular Traps (NETs) in Autoimmune Diseases: A Comprehensive Review. Autoimmun Rev (2017) 16:1160-73. doi: 10.1016/ j.autrev.2017.09.012

12. Brinkmann V. Neutrophil Extracellular Traps in the Second Decade. J Innate Immun (2018) 10:414-21. doi: 10.1159/000489829

13. Albrengues J, Shields MA, Ng D, Park CG, Ambrico A, Poindexter ME, et al. Neutrophil Extracellular Traps Produced During Inflammation Awaken Dormant Cancer Cells in Mice. Science (2018) 361:eaao4227. doi: 10.1126/ science.aao4227

14. Park J, Wysocki RW, Amoozgar Z, Maiorino L, Fein MR, Jorns J, et al. Cancer Cells Induce Metastasis-Supporting Neutrophil Extracellular DNA Traps. Sci Transl Med (2016) 8:361ra138. doi: 10.1126/scitranslmed.aag1711

15. Thalin C, Hisada Y, Lundstrom S, Mackman N, Wallen H. Neutrophil Extracellular Traps: Villains and Targets in Arterial, Venous, and CancerAssociated Thrombosis. Arterioscler Thromb Vasc Biol (2019) 39:1724-38. doi: 10.1161/ATVBAHA.119.312463

16. Jorch SK, Kubes P. An Emerging Role for Neutrophil Extracellular Traps in Noninfectious Disease. Nat Med (2017) 23:279-87. doi: 10.1038/nm.4294

17. Jung HS, Gu J, Kim JE, Nam Y, Song JW, Kim HK. Cancer Cell-Induced Neutrophil Extracellular Traps Promote Both Hypercoagulability and Cancer Progression. PLoS One (2019) 14:e0216055. doi: 10.1371/ journal.pone.0216055

18. Sorensen OE, Borregaard N. Neutrophil Extracellular Traps - the Dark Side of Neutrophils. J Clin Invest (2016) 126:1612-20. doi: 10.1172/JCI84538

19. Bonaventura A, Vecchie A, Abbate A, Montecucco F. Neutrophil Extracellular Traps and Cardiovascular Diseases: An Update. Cells (2020) 9:231. doi: 10.3390/cells9010231

\section{FUNDING}

This work was supported by a grant from Ministry of Science and Technology of the People's Republic of China (No. 2016YFC1303600) and grants from General Hospital of the Chinese People's Liberation Army (No. 2018ZD-006 and 2018MS-012).

20. Fousert E, Toes R, Desai J. Neutrophil Extracellular Traps (NETs) Take the Central Stage in Driving Autoimmune Responses. Cells (2020) 9:915. doi: 10.3390/cells9040915

21. Yipp BG, Petri B, Salina D, Jenne CN, Scott BN, Zbytnuik LD, et al. Infection-Induced NETosis Is a Dynamic Process Involving Neutrophil Multitasking In Vivo. Nat Med (2012) 18:1386-93. doi: 10.1038/nm.2847

22. Mesa MA, Vasquez G. NETosis. Autoimmune Dis (2013) 2013:651497. doi: 10.1155/2013/651497

23. Kaplan MJ, Radic M. Neutrophil Extracellular Traps: Double-Edged Swords of Innate Immunity. J Immunol (2012) 189:2689-95. doi: 10.4049/ jimmunol.1201719

24. Gupta AK, Joshi MB, Philippova M, Erne P, Hasler P, Hahn S, et al. Activated Endothelial Cells Induce Neutrophil Extracellular Traps and Are Susceptible to NETosis-Mediated Cell Death. FEBS Lett (2010) 584:3193-7. doi: 10.1016/j.febslet.2010.06.006

25. Masuda S, Nakazawa D, Shida H, Miyoshi A, Kusunoki Y, Tomaru U, et al. NETosis Markers: Quest for Specific, Objective, and Quantitative Markers. Clin Chim Acta (2016) 459:89-93. doi: 10.1016/j.cca.2016.05.029

26. Yang H, Biermann MH, Brauner JM, Liu Y, Zhao Y, Herrmann M. New Insights Into Neutrophil Extracellular Traps: Mechanisms of Formation and Role in Inflammation. Front Immunol (2016) 7:302. doi: 10.3389/ fimmu.2016.00302

27. White PC, Chicca IJ, Cooper PR, Milward MR, Chapple IL. Neutrophil Extracellular Traps in Periodontitis: A Web of Intrigue. J Dent Res (2016) 95:26-34. doi: 10.1177/0022034515609097

28. Galluzzi L, Vitale I, Aaronson SA, Abrams JM, Adam D, Agostinis P, et al Molecular Mechanisms of Cell Death: Recommendations of the Nomenclature Committee on Cell Death 2018. Cell Death Differ (2018) 25:486-541. doi: 10.1038/s41418-017-0012-4

29. Hamam HJ, Khan MA, Palaniyar N. Histone Acetylation Promotes Neutrophil Extracellular Trap Formation. Biomolecules (2019) 9:32. doi: 10.3390/biom9010032

30. Tsourouktsoglou TD, Warnatsch A, Ioannou M, Hoving D, Wang Q, Papayannopoulos V. Histones, DNA, and Citrullination Promote Neutrophil Extracellular Trap Inflammation by Regulating the Localization and Activation of TLR4. Cell Rep (2020) 31:107602. doi: 10.1016/j.celrep.2020.107602

31. Van HT, Santos MA. Histone Modifications and the DNA Double-Strand Break Response. Cell Cycle (2018) 17:2399-410. doi: 10.1080/15384101.2018.1542899

32. Kenny EF, Herzig A, Kruger R, Muth A, Mondal S, Thompson PR, et al. Diverse Stimuli Engage Different Neutrophil Extracellular Trap Pathways. Elife (2017) 6:e24437. doi: 10.7554/eLife.24437

33. Boeltz S, Amini P, Anders HJ, Andrade F, Bilyy R, Chatfield S, et al. To NET or Not to NET:current Opinions and State of the Science Regarding the Formation of Neutrophil Extracellular Traps. Cell Death Differ (2019) 26:395-408. doi: 10.1038/s41418-018-0261-x

34. Sur Chowdhury C, Giaglis S, Walker UA, Buser A, Hahn S, Hasler P. Enhanced Neutrophil Extracellular Trap Generation in Rheumatoid Arthritis: Analysis of Underlying Signal Transduction Pathways and Potential Diagnostic Utility. Arthritis Res Ther (2014) 16:R122. doi: 10.1186/ar4579

35. Hilscher MB, Sehrawat T, Arab JP, Zeng Z, Gao J, Liu M, et al. Mechanical Stretch Increases Expression of CXCL1 in Liver Sinusoidal Endothelial Cells to Recruit Neutrophils, Generate Sinusoidal Microthombi, and Promote Portal Hypertension. Gastroenterology (2019) 157:193-209.e9. doi: 10.1053/ j.gastro.2019.03.013

36. Diaz-Godinez C, Fonseca Z, Nequiz M, Laclette JP, Rosales C, Carrero JC Entamoeba Histolytica Trophozoites Induce a Rapid Non-Classical NETosis 
Mechanism Independent of NOX2-Derived Reactive Oxygen Species and PAD4 Activity. Front Cell Infect Microbiol (2018) 8:184. doi: 10.3389/ fcimb.2018.00184

37. Sorensen OE, Clemmensen SN, Dahl SL, Ostergaard O, Heegaard NH, Glenthoj A, et al. Papillon-Lefevre Syndrome Patient Reveals SpeciesDependent Requirements for Neutrophil Defenses. J Clin Invest (2014) 124:4539-48. doi: 10.1172/JCI76009

38. Rabadi M, Kim M, D’Agati V, Lee HT. Peptidyl Arginine Deiminase-4Deficient Mice Are Protected Against Kidney and Liver Injury After Renal Ischemia and Reperfusion. Am J Physiol Renal Physiol (2016) 311:F437-49. doi: 10.1152/ajprenal.00254.2016

39. Raup-Konsavage WM, Wang Y, Wang WW, Feliers D, Ruan H, Reeves WB. Neutrophil Peptidyl Arginine Deiminase-4 has a Pivotal Role in Ischemia/ Reperfusion-Induced Acute Kidney Injury. Kidney Int (2018) 93:365-74. doi: 10.1016/j.kint.2017.08.014

40. Sollberger G, Choidas A, Burn GL, Habenberger P, Di Lucrezia R, Kordes S, et al. Gasdermin D Plays a Vital Role in the Generation of Neutrophil Extracellular Traps. Sci Immunol (2018) 3:eaar6689. doi: 10.1126/sciimmunol.aar6689

41. Tall AR, Westerterp M. Inflammasomes, Neutrophil Extracellular Traps, and Cholesterol. J Lipid Res (2019) 60:721-27. doi: 10.1194/jlr.S091280

42. Ravindran M, Khan MA, Palaniyar N. Neutrophil Extracellular Trap Formation: Physiology, Pathology, and Pharmacology. Biomolecules (2019) 9:365. doi: 10.3390/biom9080365

43. Douda DN, Khan MA, Grasemann H, Palaniyar N. SK3 Channel and Mitochondrial ROS Mediate NADPH Oxidase-Independent NETosis Induced by Calcium Influx. Proc Natl Acad Sci U S A (2015) 112:2817-22. doi: $10.1073 /$ pnas. 1414055112

44. DeSouza-Vieira T, Guimaraes-Costa A, Rochael NC, Lira MN, Nascimento MT, Lima-Gomez PS, et al. Neutrophil Extracellular Traps Release Induced by Leishmania: Role of PI3Kgamma, ERK, PI3Ksigma, PKC, and [Ca2+]. J Leukoc Biol (2016) 100:801-10. doi: 10.1189/jlb.4A0615-261RR

45. Fonseca Z, Diaz-Godinez C, Mora N, Aleman OR, Uribe-Querol E, Carrero JC, et al. Entamoeba Histolytica Induce Signaling via Raf/MEK/ERK for Neutrophil Extracellular Trap (NET) Formation. Front Cell Infect Microbiol (2018) 8:226. doi: 10.3389/fcimb.2018.00226

46. Yin K, Yang Z, Gong Y, Wang D, Lin H. The Antagonistic Effect of Se on the PbWeakening Formation of Neutrophil Extracellular Traps in Chicken Neutrophils. Ecotoxicol Environ Saf (2019) 173:225-34. doi: 10.1016/ j.ecoenv.2019.02.033

47. Hu Q, Shi H, Zeng T, Liu H, Su Y, Cheng X, et al. Increased Neutrophil Extracellular Traps Activate NLRP3 and Inflammatory Macrophages in AdultOnset Still's Disease. Arthritis Res Ther (2019) 21:9. doi: 10.1186/s13075-0181800-z

48. Liu D, Yang P, Gao M, Yu T, Shi Y, Zhang M, et al. NLRP3 Activation Induced by Neutrophil Extracellular Traps Sustains Inflammatory Response in the Diabetic Wound. Clin Sci (Lond) (2019) 133:565-82. doi: 10.1042/CS20180600

49. Skendros P, Mitroulis I, Ritis K. Autophagy in Neutrophils: From Granulopoiesis to Neutrophil Extracellular Traps. Front Cell Dev Biol (2018) 6:109. doi: 10.3389/fcell.2018.00109

50. An Z, Li J, Yu J, Wang X, Gao H, Zhang W, et al. Neutrophil Extracellular Traps Induced by IL-8 Aggravate Atherosclerosis via Activation NF-kappaB Signaling in Macrophages. Cell Cycle (2019) 18:2928-38. doi: 10.1080/ 15384101.2019.1662678

51. Gonzalez-Aparicio M, Alfaro C. Influence of Interleukin-8 and Neutrophil Extracellular Trap (NET) Formation in the Tumor Microenvironment: Is There a Pathogenic Role? J Immunol Res (2019) 2019:6252138. doi: 10.1155/ $2019 / 6252138$

52. Wang S, Zheng S, Zhang Q, Yang Z, Yin K, Xu S. Atrazine Hinders PMAInduced Neutrophil Extracellular Traps in Carp via the Promotion of Apoptosis and Inhibition of ROS Burst, Autophagy and Glycolysis. Environ Pollut (2018) 243:282-91. doi: 10.1016/j.envpol.2018.08.070

53. Galkina SI, Fedorova NV, Golenkina EA, Stadnichuk VI, Sud'ina GF. Cytonemes Versus Neutrophil Extracellular Traps in the Fight of Neutrophils With Microbes. Int J Mol Sci (2020) 21:586. doi: 10.3390/ ijms 21020586

54. Cox LE, Walstein K, Vollger L, Reuner F, Bick A, Dotsch A, et al. Neutrophil Extracellular Trap Formation and Nuclease Activity in Septic Patients. BMC Anesthesiol (2020) 20:15. doi: 10.1186/s12871-019-0911-7
55. Colon DF, Wanderley CW, Franchin M, Silva CM, Hiroki CH, Castanheira FVS, et al. Neutrophil Extracellular Traps (NETs) Exacerbate Severity of Infant Sepsis. Crit Care (2019) 23:113. doi: 10.1186/s13054-019-2407-8

56. Arroyo R, Khan MA, Echaide M, Perez-Gil J, Palaniyar N. SP-D Attenuates LPS-Induced Formation of Human Neutrophil Extracellular Traps (NETs), Protecting Pulmonary Surfactant Inactivation by NETs. Commun Biol (2019) 2:470. doi: 10.1038/s42003-019-0662-5

57. Clark SR, Ma AC, Tavener SA, McDonald B, Goodarzi Z, Kelly MM, et al. Platelet TLR4 Activates Neutrophil Extracellular Traps to Ensnare Bacteria in Septic Blood. Nat Med (2007) 13:463-9. doi: 10.1038/nm1565

58. Rada B. Neutrophil Extracellular Traps. Methods Mol Biol (2019) 1982:51728. doi: 10.1007/978-1-4939-9424-3_31

59. Urban CF, Nett JE. Neutrophil Extracellular Traps in Fungal Infection. Semin Cell Dev Biol (2019) 89:47-57. doi: 10.1016/j.semcdb.2018.03.020

60. Dinallo V, Marafini I, Di Fusco D, Laudisi F, Franze E, Di Grazia A, et al. Neutrophil Extracellular Traps Sustain Inflammatory Signals in Ulcerative Colitis. J Crohns Colitis (2019) 13:772-84. doi: 10.1093/ecco-jcc/jjy215

61. Folco EJ, Mawson TL, Vromman A, Bernardes-Souza B, Franck G, Persson O, et al. Neutrophil Extracellular Traps Induce Endothelial Cell Activation and Tissue Factor Production Through Interleukin-1alpha and Cathepsin G. Arterioscler Thromb Vasc Biol (2018) 38:1901-12. doi: 10.1161/ ATVBAHA.118.311150

62. Laridan E, Martinod K, De Meyer SF. Neutrophil Extracellular Traps in Arterial and Venous Thrombosis. Semin Thromb Hemost (2019) 45:86-93. doi: 10.1055/s-0038-1677040

63. Gao H, Wang X, Lin C, An Z, Yu J, Cao H, et al. Exosomal MALAT1 Derived From Ox-LDL-Treated Endothelial Cells Induce Neutrophil Extracellular Traps to Aggravate Atherosclerosis. Biol Chem (2020) 401:367-76. doi: 10.1515/hsz-2019-0219

64. Wang YP, Guo Y, Wen PS, Zhao ZZ, Xie J, Yang K, et al. Three Ingredients of Safflower Alleviate Acute Lung Injury and Inhibit NET Release Induced by Lipopolysaccharide. Mediators Inflamm (2020) 2020:2720369. doi: 10.1155/2020/2720369

65. Wei Z, Wang J, Wang Y, Wang C, Liu X, Han Z, et al. Effects of Neutrophil Extracellular Traps on Bovine Mammary Epithelial Cells In Vitro. Front Immunol (2019) 10:1003. doi: 10.3389/fimmu.2019.01003

66. Li T, Wang C, Liu Y, Li B, Zhang W, Wang L, et al. Neutrophil Extracellular Traps Induce Intestinal Damage and Thrombotic Tendency in Inflammatory Bowel Disease. J Crohns Colitis (2020) 14:240-53. doi: 10.1093/ecco-jcc/jjz132

67. Kubiritova Z, Radvanszky J, Gardlik R. Cell-Free Nucleic Acids and Their Emerging Role in the Pathogenesis and Clinical Management of Inflammatory Bowel Disease. Int J Mol Sci (2019) 20:3662. doi: 10.3390/ ijms20153662

68. Gottlieb Y, Elhasid R, Berger-Achituv S, Brazowski E, Yerushalmy-Feler A, Cohen S. Neutrophil Extracellular Traps in Pediatric Inflammatory Bowel Disease. Pathol Int (2018) 68:517-23. doi: 10.1111/pin.12715

69. Manda-Handzlik A, Demkow U. The Brain Entangled: The Contribution of Neutrophil Extracellular Traps to the Diseases of the Central Nervous System. Cells (2019) 8:1477. doi: 10.3390/cells8121477

70. Paryzhak S, Dumych T, Mahorivska I, Boichuk M, Bila G, Peshkova S, et al. Neutrophil-Released Enzymes can Influence Composition of Circulating Immune Complexes in Multiple Sclerosis. Autoimmunity (2018) 51:297303. doi: 10.1080/08916934.2018.1514390

71. Josefs T, Barrett TJ, Brown EJ, Quezada A, Wu X, Voisin M, et al. Neutrophil Extracellular Traps Promote Macrophage Inflammation and Impair Atherosclerosis Resolution in Diabetic Mice. JCI Insight (2020) 5:e134796. doi: $10.1172 /$ jci.insight. 134796

72. Doring Y, Libby P, Soehnlein O. Neutrophil Extracellular Traps Participate in Cardiovascular Diseases: Recent Experimental and Clinical Insights. Circ Res (2020) 126:1228-41. doi: 10.1161/CIRCRESAHA.120.315931

73. Ducroux C, Di Meglio L, Loyau S, Delbosc S, Boisseau W, Deschildre C, et al. Thrombus Neutrophil Extracellular Traps Content Impair tPA-Induced Thrombolysis in Acute Ischemic Stroke. Stroke (2018) 49:754-57. doi: 10.1161/STROKEAHA.117.019896

74. Granger V, Peyneau M, Chollet-Martin S, de Chaisemartin L. Neutrophil Extracellular Traps in Autoimmunity and Allergy: Immune Complexes at Work. Front Immunol (2019) 10:2824. doi: 10.3389/fimmu.2019.02824 
75. Demers M, Krause DS, Schatzberg D, Martinod K, Voorhees JR, Fuchs TA, et al. Cancers Predispose Neutrophils to Release Extracellular DNA Traps That Contribute to Cancer-Associated Thrombosis. Proc Natl Acad Sci U S A (2012) 109:13076-81. doi: 10.1073/pnas.1200419109

76. Houghton AM, Rzymkiewicz DM, Ji H, Gregory AD, Egea EE, Metz HE, et al. Neutrophil Elastase-Mediated Degradation of IRS-1 Accelerates Lung Tumor Growth. Nat Med (2010) 16:219-23. doi: 10.1038/nm.2084

77. Gregory AD, Hale P, Perlmutter DH, Houghton AM. Clathrin Pit-Mediated Endocytosis of Neutrophil Elastase and Cathepsin G by Cancer Cells. J Biol Chem (2012) 287:35341-50. doi: 10.1074/jbc.M112.385617

78. Acuff HB, Carter KJ, Fingleton B, Gorden DL, Matrisian LM. Matrix Metalloproteinase-9 From Bone Marrow-Derived Cells Contributes to Survival But Not Growth of Tumor Cells in the Lung Microenvironment. Cancer Res (2006) 66:259-66. doi: 10.1158/0008-5472.CAN-05-2502

79. Teijeira A, Garasa S, Gato M, Alfaro C, Migueliz I, Cirella A, et al. CXCR1 and CXCR2 Chemokine Receptor Agonists Produced by Tumors Induce Neutrophil Extracellular Traps That Interfere With Immune Cytotoxicity. Immunity (2020) 52:856-71.e8. doi: 10.1016/j.immuni.2020.03.001

80. Ireland AS, Oliver TG. Neutrophils Create an ImpeNETrable Shield Between Tumor and Cytotoxic Immune Cells. Immunity (2020) 52:729-31. doi: 10.1016/j.immuni.2020.04.009

81. Yazdani HO, Roy E, Comerci AJ, van der Windt DJ, Zhang H, Huang H, et al. Neutrophil Extracellular Traps Drive Mitochondrial Homeostasis in Tumors to Augment Growth. Cancer Res (2019) 79:5626-39. doi: 10.1158/ 0008-5472.CAN-19-0800

82. Stoiber D, Assinger A. Platelet-Leukocyte Interplay in Cancer Development and Progression. Cells (2020) 9:855. doi: 10.3390/cells9040855

83. Mansour A, Bachelot-Loza C, Nesseler N, Gaussem P, Gouin-Thibault I. P2Y12 Inhibition Beyond Thrombosis: Effects on Inflammation. Int J Mol Sci (2020) 21:1391. doi: 10.3390/ijms21041391

84. Schlesinger M. Role of Platelets and Platelet Receptors in Cancer Metastasis. J Hematol Oncol (2018) 11:125. doi: 10.1186/s13045-018-0669-2

85. Almeida VH, Rondon AMR, Gomes T, Monteiro RQ. Novel Aspects of Extracellular Vesicles as Mediators of Cancer-Associated Thrombosis. Cells (2019) 8:716. doi: 10.3390/cells8070716

86. Rayes RF, Mouhanna JG, Nicolau I, Bourdeau F, Giannias B, Rousseau S, et al. Primary Tumors Induce Neutrophil Extracellular Traps With Targetable Metastasis Promoting Effects. JCI Insight (2019) 5:e128008. doi: $10.1172 /$ jci.insight. 128008

87. Takesue S, Ohuchida K, Shinkawa T, Otsubo Y, Matsumoto S, Sagara A, et al. Neutrophil Extracellular Traps Promote Liver Micrometastasis in Pancreatic Ductal Adenocarcinoma via the Activation of Cancerassociated Fibroblasts. Int J Oncol (2020) 56:596-605. doi: 10.3892/ijo.2019.4951

88. Gregoire M, Guilloton F, Pangault C, Mourcin F, Sok P, Latour M, et al. Neutrophils Trigger a NF-kappaB Dependent Polarization of TumorSupportive Stromal Cells in Germinal Center B-Cell Lymphomas. Oncotarget (2015) 6:16471-87. doi: 10.18632/oncotarget.4106

89. Presta M, Chiodelli P, Giacomini A, Rusnati M, Ronca R. Fibroblast Growth Factors (FGFs) in Cancer: FGF Traps as a New Therapeutic Approach. Pharmacol Ther (2017) 179:171-87. doi: 10.1016/j.pharmthera.2017.05.013

90. Liu Y, Liu L. The Pro-Tumor Effect and the Anti-Tumor Effect of Neutrophils Extracellular Traps. Biosci Trends (2020) 13:469-75. doi: 10.5582/bst.2019.01326

91. Triner D, Devenport SN, Ramakrishnan SK, Ma X, Frieler RA, Greenson JK, et al. Neutrophils Restrict Tumor-Associated Microbiota to Reduce Growth and Invasion of Colon Tumors in Mice. Gastroenterology (2019) 156:146782. doi: $10.1053 /$ j.gastro.2018.12.003

92. Zhou J, Yang Y, Gan T, Li Y, Hu F, Hao N, et al. Lung Cancer Cells Release High Mobility Group Box 1 and Promote the Formation of Neutrophil Extracellular Traps. Oncol Lett (2019) 18:181-8. doi: 10.3892/ol.2019.10290

93. Yang LY, Luo Q, Lu L, Zhu WW, Sun HT, Wei R, et al. Increased Neutrophil Extracellular Traps Promote Metastasis Potential of Hepatocellular Carcinoma via Provoking Tumorous Inflammatory Response. J Hematol Oncol (2020) 13:3. doi: 10.1186/s13045-019-0836-0

94. Scandolara TB, Panis C. Neutrophil Traps, Anti-Myeloperoxidase Antibodies and Cancer: Are They Linked? Immunol Lett (2020) 221:33-8. doi: 10.1016/j.imlet.2020.02.011
95. Evavold CL, Kagan JC. Inflammasomes: Threat-Assessment Organelles of the Innate Immune System. Immunity (2019) 51:609-24. doi: 10.1016/ j.immuni.2019.08.005

96. Shao BZ, Wang SL, Pan P, Yao J, Wu K, Li ZS, et al. Targeting NLRP3 Inflammasome in Inflammatory Bowel Disease: Putting Out the Fire of Inflammation. Inflammation (2019) 42:1147-59. doi: 10.1007/s10753-01901008-y

97. Schroder K, Tschopp J. The Inflammasomes. Cell (2010) 140:821-32. doi: 10.1016/j.cell.2010.01.040

98. He Y, Zeng MY, Yang D, Motro B, Nunez G. NEK7 is an Essential Mediator of NLRP3 Activation Downstream of Potassium Efflux. Nature (2016) 530:354-7. doi: 10.1038/nature16959

99. Shao BZ, Xu ZQ, Han BZ, Su DF, Liu C. NLRP3 Inflammasome and its Inhibitors: A Review. Front Pharmacol (2015) 6:262. doi: 10.3389/ fphar.2015.00262

100. Shao BZ, Cao Q, Liu C. Targeting NLRP3 Inflammasome in the Treatment of CNS Diseases. Front Mol Neurosci (2018) 11:320. doi: 10.3389/ fnmol.2018.00320

101. Shao BZ, Wei W, Ke P, Xu ZQ, Zhou JX, Liu C. Activating Cannabinoid Receptor 2 Alleviates Pathogenesis of Experimental Autoimmune Encephalomyelitis via Activation of Autophagy and Inhibiting NLRP3 Inflammasome. CNS Neurosci Ther (2014) 20:1021-8. doi: 10.1111/ cns. 12349

102. Ke P, Shao BZ, Xu ZQ, Chen XW, Wei W, Liu C. Activating Alpha7 Nicotinic Acetylcholine Receptor Inhibits NLRP3 Inflammasome Through Regulation of Beta-Arrestin-1. CNS Neurosci Ther (2017) 23:875-84. doi: $10.1111 /$ cns. 12758

103. Rathinam VA, Fitzgerald KA. Inflammasome Complexes: Emerging Mechanisms and Effector Functions. Cell (2016) 165:792-800. doi: 10.1016/j.cell.2016.03.046

104. Karki R, Man SM, Kanneganti TD. Inflammasomes and Cancer. Cancer Immunol Res (2017) 5:94-9. doi: 10.1158/2326-6066.CIR-16-0269

105. Cao X, Xu J. Insights Into Inflammasome and its Research Advances in Cancer. Tumori (2019) 105:456-64. doi: 10.1177/0300891619868007

106. Van Gorp H, Lamkanfi M. The Emerging Roles of InflammasomeDependent Cytokines in Cancer Development. EMBO Rep (2019) 20: e47575. doi: 10.15252/embr.201847575

107. Guo B, Fu S, Zhang J, Liu B, Li Z. Targeting Inflammasome/IL-1 Pathways for Cancer Immunotherapy. Sci Rep (2016) 6:36107. doi: 10.1038/srep36107

108. Huang CF, Chen L, Li YC, Wu L, Yu GT, Zhang WF, et al. NLRP3 Inflammasome Activation Promotes Inflammation-Induced Carcinogenesis in Head and Neck Squamous Cell Carcinoma. J Exp Clin Cancer Res (2017) 36:116. doi: 10.1186/s13046-017-0589-y

109. Wang H, Luo Q, Feng X, Zhang R, Li J, Chen F. NLRP3 Promotes Tumor Growth and Metastasis in Human Oral Squamous Cell Carcinoma. BMC Cancer (2018) 18:500. doi: 10.1186/s12885-018-4403-9

110. Ershaid N, Sharon Y, Doron H, Raz Y, Shani O, Cohen N, et al. NLRP3 Inflammasome in Fibroblasts Links Tissue Damage With Inflammation in Breast Cancer Progression and Metastasis. Nat Commun (2019) 10:4375. doi: 10.1038/s41467-019-12370-8

111. Lachowicz-Scroggins ME, Dunican EM, Charbit AR, Raymond W, Looney MR, Peters MC, et al. Extracellular DNA, Neutrophil Extracellular Traps, and Inflammasome Activation in Severe Asthma. Am J Respir Crit Care Med (2019) 199:1076-85. doi: 10.1164/rccm.201810-1869OC

112. Warnatsch A, Ioannou M, Wang Q, Papayannopoulos V. Inflammation. Neutrophil Extracellular Traps License Macrophages for Cytokine Production in Atherosclerosis. Science (2015) 349:316-20. doi: 10.1126/ science.aaa8064

113. Elssner A, Duncan M, Gavrilin M, Wewers MD. A Novel P2X7 Receptor Activator, the Human Cathelicidin-Derived Peptide LL37, Induces IL-1 Beta Processing and Release. J Immunol (2004) 172:4987-94. doi: 10.4049/ jimmunol.172.8.4987

114. Meyer-Hoffert U, Wiedow O. Neutrophil Serine Proteases: Mediators of Innate Immune Responses. Curr Opin Hematol (2011) 18:19-24. doi: 10.1097/MOH.0b013e32834115d1

115. Jorgensen I, Lopez JP, Laufer SA, Miao EA. IL-1beta, IL-18, and Eicosanoids Promote Neutrophil Recruitment to Pore-Induced Intracellular Traps 
Following Pyroptosis. Eur J Immunol (2016) 46:2761-66. doi: 10.1002/ eji.201646647

116. Yim WW, Mizushima N. Lysosome Biology in Autophagy. Cell Discov (2020) 6:6. doi: 10.1038/s41421-020-0141-7

117. Chang NC. Autophagy and Stem Cells: Self-Eating for Self-Renewal. Front Cell Dev Biol (2020) 8:138. doi: 10.3389/fcell.2020.00138

118. Allen EA, Baehrecke EH. Autophagy in Animal Development. Cell Death Differ (2020) 27:903-18. doi: 10.1038/s41418-020-0497-0

119. Wang P, Shao BZ, Deng Z, Chen S, Yue Z, Miao CY. Autophagy in Ischemic Stroke. Prog Neurobiol (2018) 163-164:98-117. doi: 10.1016/ j.pneurobio.2018.01.001

120. Shao BZ, Han BZ, Zeng YX, Su DF, Liu C. The Roles of Macrophage Autophagy in Atherosclerosis. Acta Pharmacol Sin (2016) 37:150-6. doi: 10.1038/aps.2015.87

121. Wang SL, Shao BZ, Zhao SB, Fang J, Gu L, Miao CY, et al. Impact of Paneth Cell Autophagy on Inflammatory Bowel Disease. Front Immunol (2018) 9:693. doi: 10.3389/fimmu.2018.00693

122. Van Noorden R, Ledford H. Medicine Nobel for Research on How Cells 'Eat Themselves'. Nature (2016) 538:18-9. doi: 10.1038/nature.2016.20721

123. Klionsky DJ, Abdelmohsen K, Abe A, Abedin MJ, Abeliovich H, Acevedo Arozena A, et al. Guidelines for the Use and Interpretation of Assays for Monitoring Autophagy (3rd Edition). Autophagy (2016) 12:1-222. doi: 10.1080/15548627.2015.1100356

124. Wang SL, Shao BZ, Zhao SB, Chang X, Wang P, Miao CY, et al. Intestinal Autophagy Links Psychosocial Stress With Gut Microbiota to Promote Inflammatory Bowel Disease. Cell Death Dis (2019) 10:391. doi: 10.1038/ s41419-019-1634-x

125. Shao BZ, Wang SL, Fang J, Li ZS, Bai Y, Wu K. Alpha7 Nicotinic Acetylcholine Receptor Alleviates Inflammatory Bowel Disease Through Induction of AMPK-mTOR-P70s6k-Mediated Autophagy. Inflammation (2019) 42:1666-79. doi: 10.1007/s10753-019-01027-9

126. Shao BZ, Ke P, Xu ZQ, Wei W, Cheng MH, Han BZ, et al. Autophagy Plays an Important Role in Anti-Inflammatory Mechanisms Stimulated by Alpha7 Nicotinic Acetylcholine Receptor. Front Immunol (2017) 8:553. doi: 10.3389/ fimmu.2017.00553

127. Glick D, Barth S, Macleod KF. Autophagy: Cellular and Molecular Mechanisms. J Pathol (2010) 221:3-12. doi: 10.1002/path.2697

128. Parzych KR, Klionsky DJ. An Overview of Autophagy: Morphology, Mechanism, and Regulation. Antioxid Redox Signal (2014) 20:460-73. doi: 10.1089/ars.2013.5371

129. Ravanan P, Srikumar IF, Talwar P. Autophagy: The Spotlight for Cellular Stress Responses. Life Sci (2017) 188:53-67. doi: 10.1016/j.lfs.2017.08.029

130. Onorati AV, Dyczynski M, Ojha R, Amaravadi RK. Targeting Autophagy in Cancer. Cancer (2018) 124:3307-18. doi: 10.1002/cncr.31335

131. Yun CW, Lee SH. The Roles of Autophagy in Cancer. Int J Mol Sci (2018) 19:3466. doi: 10.3390/ijms19113466

132. Fu Y, Gu Q, Luo L, Xu J, Luo Y, Xia F, et al. New Anti-Cancer Strategy to Suppress Colorectal Cancer Growth Through Inhibition of ATG4B and Lysosome Function. Cancers (Basel) (2020) 12:1523. doi: 10.3390/ cancers 12061523

133. Bian Y, Zeng H, Tao H, Huang L, Du Z, Wang J, et al. A Pectin-Like Polysaccharide From Polygala Tenuifolia Inhibits Pancreatic Cancer Cell Growth In Vitro and In Vivo by Inducing Apoptosis and Suppressing Autophagy. Int J Biol Macromol (2020) 162:107-15. doi: 10.1016/ j.ijbiomac.2020.06.054

134. Jiang $\mathrm{H}$, Chen $\mathrm{H}$, Jin $\mathrm{C}$, Mo J, Wang $\mathrm{H}$. Nobiletin Flavone Inhibits the Growth and Metastasis of Human Pancreatic Cancer Cells via Induction of Autophagy, G0/G1 Cell Cycle Arrest and Inhibition of NF-kB Signalling Pathway. J BUON (2020) 25:1070-75.

135. Ma R, Li T, Cao M, Si Y, Wu X, Zhao L, et al. Extracellular DNA Traps Released by Acute Promyelocytic Leukemia Cells Through Autophagy. Cell Death Dis (2016) 7:e2283. doi: 10.1038/cddis.2016.186

136. Boone BA, Orlichenko L, Schapiro NE, Loughran P, Gianfrate GC, Ellis JT, et al. The Receptor for Advanced Glycation End Products (RAGE) Enhances Autophagy and Neutrophil Extracellular Traps in Pancreatic Cancer. Cancer Gene Ther (2015) 22:326-34. doi: 10.1038/cgt.2015.21

137. Boone BA, Murthy P, Miller-Ocuin J, Doerfler WR, Ellis JT, Liang X, et al. Chloroquine Reduces Hypercoagulability in Pancreatic Cancer Through
Inhibition of Neutrophil Extracellular Traps. BMC Cancer (2018) 18:678. doi: 10.1186/s12885-018-4584-2

138. Lin CF, Chien SY, Chen CL, Hsieh CY, Tseng PC, Wang YC. IFN-Gamma Induces Mimic Extracellular Trap Cell Death in Lung Epithelial Cells Through Autophagy-Regulated DNA Damage. J Interferon Cytokine Res (2016) 36:100-12. doi: 10.1089/jir.2015.0011

139. Shi L, Yao H, Liu Z, Xu M, Tsung A, Wang Y. Endogenous PAD4 in Breast Cancer Cells Mediates Cancer Extracellular Chromatin Network Formation and Promotes Lung Metastasis. Mol Cancer Res (2020) 18:735-47. doi: 10.1158/1541-7786.MCR-19-0018

140. Martins-Cardoso K, Almeida VH, Bagri KM, Rossi MID, Mermelstein CS, Konig S, et al. Neutrophil Extracellular Traps (NETs) Promote ProMetastatic Phenotype in Human Breast Cancer Cells Through EpithelialMesenchymal Transition. Cancers (Basel) (2020) 12:735-47. doi: 10.3390/ cancers 12061542

141. Yang L, Liu Q, Zhang X, Liu X, Zhou B, Chen J, et al. DNA of Neutrophil Extracellular Traps Promotes Cancer Metastasis via CCDC25. Nature (2020) 12:1542. doi: 10.1038/s41586-020-2394-6

142. Gomes T, Varady CBS, Lourenco AL, Mizurini DM, Rondon AMR, Leal AC, et al. IL-1beta Blockade Attenuates Thrombosis in a Neutrophil Extracellular Trap-Dependent Breast Cancer Model. Front Immunol (2019) 10:2088. doi: 10.3389/fimmu.2019.02088

143. Li Y, Yang Y, Gan T, Zhou J, Hu F, Hao N, et al. Extracellular RNAs From Lung Cancer Cells Activate Epithelial Cells and Induce Neutrophil Extracellular Traps. Int J Oncol (2019) 55:69-80. doi: 10.3892/ijo.2019.4808

144. Li Z, Lin Y, Zhang S, Zhou L, Yan G, Wang Y, et al. Emodin Regulates Neutrophil Phenotypes to Prevent Hypercoagulation and Lung Carcinogenesis. J Transl Med (2019) 17:90. doi: 10.1186/s12967-019-1838-y

145. Zhang Y, Wang C, Yu M, Zhao X, Du J, Li Y, et al. Neutrophil Extracellular Traps Induced by Activated Platelets Contribute to Procoagulant Activity in Patients With Colorectal Cancer. Thromb Res (2019) 180:87-97. doi: 10.1016/j.thromres.2019.06.005

146. Rayes RF, Vourtzoumis P, Bou Rjeily M, Seth R, Bourdeau F, Giannias B, et al. Neutrophil Extracellular Trap-Associated CEACAM1 as a Putative Therapeutic Target to Prevent Metastatic Progression of Colon Carcinoma. J Immunol (2020) 204:2285-94. doi: 10.4049/jimmunol.1900240

147. Shang A, Gu C, Zhou C, Yang Y, Chen C, Zeng B, et al. Exosomal KRAS Mutation Promotes the Formation of Tumor-Associated Neutrophil Extracellular Traps and Causes Deterioration of Colorectal Cancer by Inducing IL-8 Expression. Cell Commun Signal (2020) 18:52. doi: 10.1186/ s12964-020-0517-1

148. Yang L, Liu L, Zhang R, Hong J, Wang Y, Wang J, et al. IL-8 Mediates a Positive Loop Connecting Increased Neutrophil Extracellular Traps (NETs) and Colorectal Cancer Liver Metastasis. J Cancer (2020) 11:4384-96. doi: $10.7150 /$ jca. 44215

149. Yu M, Li T, Li B, Liu Y, Wang L, Zhang J, et al. Phosphatidylserine-Exposing Blood Cells, Microparticles and Neutrophil Extracellular Traps Increase Procoagulant Activity in Patients With Pancreatic Cancer. Thromb Res (2020) 188:5-16. doi: 10.1016/j.thromres.2020.01.025

150. Jin W, Yin H, Li H, Yu XJ, Xu HX, Liu L. Neutrophil Extracellular DNA Traps Promote Pancreatic Cancer Cells Migration and Invasion by Activating EGFR/ERK Pathway. J Cell Mol Med (2021) 25:5443-56. doi: $10.1111 / \mathrm{jcmm} .16555$

151. Li M, Lin C, Deng H, Strnad J, Bernabei L, Vogl DT, et al. A Novel Peptidylarginine Deiminase 4 (PAD4) Inhibitor BMS-P5 Blocks Formation of Neutrophil Extracellular Traps and Delays Progression of Multiple Myeloma. Mol Cancer Ther (2020) 180:87-97. doi: 10.1158/1535-7163.MCT-19-1020

152. Craver BM, Ramanathan G, Hoang S, Chang X, Mendez Luque LF, Brooks S, et al. N-Acetylcysteine Inhibits Thrombosis in a Murine Model of Myeloproliferative Neoplasm. Blood Adv (2020) 4:312-21. doi: 10.1182/ bloodadvances. 2019000967

153. Wolach O, Sellar RS, Martinod K, Cherpokova D, McConkey M, Chappell RJ, et al. Increased Neutrophil Extracellular Trap Formation Promotes Thrombosis in Myeloproliferative Neoplasms. Sci Transl Med (2018) 10:52. doi: 10.1126/scitranslmed.aan8292

154. Risnik D, Elias EE, Keitelman I, Colado A, Podaza E, Cordini G, et al. The Effect of Ibrutinib on Neutrophil and Gammadelta T Cell Functions. Leuk Lymphoma (2020) 11(15):4384-96. doi: 10.1080/10428194.2020.1753043 
155. Thalin C, Demers M, Blomgren B, Wong SL, von Arbin M, von Heijne A, et al. NETosis Promotes Cancer-Associated Arterial Microthrombosis Presenting as Ischemic Stroke With Troponin Elevation. Thromb Res (2016) 139:56-64. doi: 10.1016/j.thromres.2016.01.009

156. Zha C, Meng X, Li L, Mi S, Qian D, Li Z, et al. Neutrophil Extracellular Traps Mediate the Crosstalk Between Glioma Progression and the Tumor Microenvironment via the HMGB1/RAGE/IL-8 Axis. Cancer Biol Med (2020) 17:154-68. doi: 10.20892/j.issn.2095-3941.2019.0353

157. Blenman KRM, Wang J, Cowper S, Bosenberg M. Pathology of Spontaneous and Immunotherapy-Induced Tumor Regression in a Murine Model of Melanoma. Pigment Cell Melanoma Res (2019) 32:448-57. doi: 10.1111/ pcmr.12769

158. Schedel F, Mayer-Hain S, Pappelbaum KI, Metze D, Stock M, Goerge T, et al. Evidence and Impact of Neutrophil Extracellular Traps in Malignant Melanoma. Pigment Cell Melanoma Res (2020) 33:63-73. doi: 10.1111/pcmr.12818

159. Andzinski L, Kasnitz N, Stahnke S, Wu CF, Gereke M, von KockritzBlickwede $\mathrm{M}$, et al. Type I IFNs Induce Anti-Tumor Polarization of Tumor Associated Neutrophils in Mice and Human. Int J Cancer (2016) 138:1982-93. doi: 10.1002/ijc.29945

160. Harbeck N, Gnant M. Breast Cancer. Lancet (2017) 389:1134-50. doi: 10.1016/S0140-6736(16)31891-8

161. Hirsch FR, Scagliotti GV, Mulshine JL, Kwon R, Curran WJ Jr, Wu YL, et al. Lung Cancer: Current Therapies and New Targeted Treatments. Lancet (2017) 389:299-311. doi: 10.1016/S0140-6736(16)30958-8

162. Arpinati L, Shaul ME, Kaisar-Iluz N, Mali S, Mahroum S, Fridlender ZG. NETosis in Cancer: A Critical Analysis of the Impact of Cancer on Neutrophil Extracellular Trap (NET) Release in Lung Cancer Patients vs. Mice. Cancer Immunol Immunother (2020) 69:199-213. doi: 10.1007/ s00262-019-02474-x

163. Dekker E, Tanis PJ, Vleugels JLA, Kasi PM, Wallace MB. Colorectal Cancer. Lancet (2019) 394:1467-80. doi: 10.1016/S0140-6736(19)32319-0

164. Brenner H, Kloor M, Pox CP. Colorectal Cancer. Lancet (2014) 383:1490502. doi: 10.1016/S0140-6736(13)61649-9

165. Richardson JJR, Hendrickse C, Gao-Smith F, Thickett DR. Neutrophil Extracellular Trap Production in Patients With Colorectal Cancer In Vitro. Int J Inflamm (2017) 2017:4915062. doi: 10.1155/2017/4915062

166. Kamisawa T, Wood LD, Itoi T, Takaori K. Pancreatic Cancer. Lancet (2016) 388:73-85. doi: 10.1016/S0140-6736(16)00141-0

167. Jin W, Xu HX, Zhang SR, Li H, Wang WQ, Gao HL, et al. Tumor-Infiltrating NETs Predict Postsurgical Survival in Patients With Pancreatic Ductal Adenocarcinoma. Ann Surg Oncol (2019) 26:635-43. doi: 10.1245/s10434018-6941-4

168. Campello E, Ilich A, Simioni P, Key NS. The Relationship Between Pancreatic Cancer and Hypercoagulability: A Comprehensive Review on Epidemiological and Biological Issues. Br J Cancer (2019) 121:359-71. doi: 10.1038/s41416-019-0510-X
169. Hisada Y, Grover SP, Maqsood A, Houston R, Ay C, Noubouossie DF, et al. Neutrophils and Neutrophil Extracellular Traps Enhance Venous Thrombosis in Mice Bearing Human Pancreatic Tumors. Haematologica (2020) 105:218-25. doi: 10.3324/haematol.2019.217083

170. Kennedy A. Make Blood Cancer Visible. Lancet Oncol (2017) 18:1577. doi: 10.1016/S1470-2045(17)30849-5

171. Fagerhol MK, Johnson E, Tangen JM, Hollan I, Mirlashari MR, NissenMeyer LSH, et al. NETs Analysed by Novel Calprotectin-Based Assays in Blood Donors and Patients With Multiple Myeloma or Rheumatoid Arthritis: A Pilot Study. Scand J Immunol (2020) 91:e12870. doi: 10.1111/ sji. 12870

172. Balachandran AA, Larcher LM, Chen S, Veedu RN. Therapeutically Significant MicroRNAs in Primary and Metastatic Brain Malignancies. Cancers (Basel) (2020) 12:645-59. doi: 10.3390/cancers12092534

173. Louis DN, Perry A, Reifenberger G, von Deimling A, Figarella-Branger D, Cavenee WK, et al. The 2016 World Health Organization Classification of Tumors of the Central Nervous System: A Summary. Acta Neuropathol (2016) 131:803-20. doi: 10.1007/s00401-016-1545-1

174. Pabinger I, Posch F. Flamethrowers: Blood Cells and Cancer Thrombosis Risk. Hematol Am Soc Hematol Educ Program (2014) 2014:410-7. doi: 10.1182/asheducation-2014.1.410

175. Linares MA, Zakaria A, Nizran P. Skin Cancer. Prim Care (2015) 42:645-59. doi: 10.1016/j.pop.2015.07.006

176. Marone G, Schroeder JT, Mattei F, Loffredo S, Gambardella AR, Poto R, et al. Is There a Role for Basophils in Cancer? Front Immunol (2020) 11:2103. doi: 10.3389/fimmu.2020.02103

177. Mussbacher M, Salzmann M, Brostjan C, Hoesel B, Schoergenhofer C, Datler $\mathrm{H}$, et al. Cell Type-Specific Roles of NF-kappaB Linking Inflammation and Thrombosis. Front Immunol (2019) 10:85. doi: 10.3389/fimmu.2019.00085

Conflict of Interest: The authors declare that the research was conducted in the absence of any commercial or financial relationships that could be construed as a potential conflict of interest.

Publisher's Note: All claims expressed in this article are solely those of the authors and do not necessarily represent those of their affiliated organizations, or those of the publisher, the editors and the reviewers. Any product that may be evaluated in this article, or claim that may be made by its manufacturer, is not guaranteed or endorsed by the publisher.

Copyright (c) 2021 Shao, Yao, Li, Chai and Linghu. This is an open-access article distributed under the terms of the Creative Commons Attribution License (CC BY). The use, distribution or reproduction in other forums is permitted, provided the original author(s) and the copyright owner(s) are credited and that the original publication in this journal is cited, in accordance with accepted academic practice. No use, distribution or reproduction is permitted which does not comply with these terms. 